\title{
Implicações éticas e metodológicas de uma cartografia no sistema socioeducativo: surpresas, angústias e caminhos possíveis
}

\author{
Ethical and methodological implications of a cartography in the Socio- \\ educational System: surprises, anguishes and possible paths
}

\section{Implicaciones éticas y metodológicas de una cartografía en el Sistema Socioeducativo: sorpresas, angustias y caminos posibles}

\author{
Jimena de Garay Hernández ${ }^{\mathrm{a}}{ }^{\mathbb{D}}$; Patricia Castro de Oliveira e Silva ${ }^{\mathrm{b}} \mathbb{C}^{\mathbb{D}}$; Anna Paula Uziel ${ }^{\mathrm{C}}$ \\ e Simone Peres ${ }^{\mathrm{d}}$ (D)
}

${ }^{a}$ Psicóloga, doutora em Psicologia Social pela Universidade do Estado do Rio de Janeiro. Pesquisadora do LIDIS/UERJ e do GEPSID/UERJ. Universidade do Estado do Rio de Janeiro, Rio de Janeiro, RJ, Brasil - E-mail: jime_degaray@hotmail.com

${ }^{\text {b }}$ Psicóloga, doutora em Psicossociologia de Comunidades e Ecologia Social pela Universidade Federal do Rio de Janeiro. Pósdoutoranda em Psicologia Social na Universidade do Estado do Rio de Janeiro, RJ, Brasil - E-mail: patriciacastropsi@gmail.com

${ }^{c}$ Psicóloga, doutora em Ciências Sociais pela Universidade Estadual de Campinas. Professora associada no Instituto de Psicologia da Universidade do Estado do Rio de Janeiro e no PPGPS /UERJ, Rio de Janeiro, RJ, Brasil - E-mail: uzielap@gmail.com

${ }^{\text {d }}$ Psicóloga, doutora em Saúde Coletiva pela Universidade do Estado do Rio de Janeiro. Professora do Instituto de Psicologia da Universidade Federal do Rio de Janeiro e do e do curso de pós-graduação EICOS/UFRJ, Rio de Janeiro, RJ, Brasil - E-mail: ouvinhaperes@uol.com.br

Resumo: Este texto relata e põe em análise os caminhos percorridos em uma pesquisa cartográfica desenvolvida a partir de questões de gênero e sexualidade em unidades de internação do Sistema Socioeducativo do Rio de Janeiro. Em meio a surpresas, angústias e desafios, discutimos aspectos éticos e metodológicos do nosso percurso como pesquisadoras, a partir da cartografia como uma perspectiva ético-político-estética-metodológica que tem como objetivo, mote ou pretexto acompanhar processos. Cartografar é abrir-se ao encontro, perseguir redes de forças, mergulhar em intensidades. Isso possibilita parcerias e permite que as tensões e potências do encontro das pesquisadoras no campo se constituam também como seus analisadores.

Palavras-chave: Sistema Socioeducativo. Gênero. Sexualidade. Cartografia.

\begin{abstract}
This paper reports and analyzes the paths taken in a cartographic research developed from questions of gender and sexuality in deprivation of liberty units of the Socio-educational System (juvenile system) of Rio de Janeiro. In the midst of surprises, anguishes and challenges, we discuss ethical and methodological aspects of our journey as researchers, from the cartography as an ethical-political-aesthetic-methodological perspective which objective, motto or pretext is to follow processes. To cartography is to open up to the encounter, pursue networks of forces, plunge into intensities. This allows partnerships and enables the tensions and powers of the meeting of the researchers in the field to be also its analyzers.
\end{abstract}

Keywords: Juvenile system. Gender. Sexuality. Cartography. 
Resumen: Este texto relata y pone en análisis los caminos recorridos en una investigación cartográfica desarrollada a partir de cuestiones de género y sexualidad en unidades de internación del Sistema Socioeducativo de Río de Janeiro. En medio de sorpresas, angustias y desafíos, discutimos aspectos éticos y metodológicos de nuestro recorrido como investigadoras, a partir de la cartografía como una perspectiva ético-político-estética-metodológica que tiene como objetivo, mote o pretexto acompañar procesos. Cartografiar es abrirse al encuentro, perseguir redes de fuerzas, zambullirse en intensidades. Eso posibilita alianzas y permite que las tensiones y potencias del encuentro de las investigadoras en el campo se constituyan también como sus analizadores.

Palabras clave: Sistema Socioeducativo. Género. Sexualidad. Cartografía.

\section{Como citar o artigo:}

DE GARAY HERNÁNDEZ, J. et al. Implicações éticas e metodológicas de uma cartografia no sistema socioeducativo: surpresas, angústias e caminhos possíveis. Revista de Ciências Humanas, Florianópolis, v. 52, 2018. DOI: $10.5007 / 2178-4582.2018 .57163$

\section{INTRODUÇÃO}

O presente artigo discorre sobre alguns desafios de uma pesquisa realizada no Sistema Socioeducativo do Rio de Janeiro. Esta pesquisa-extensão surgiu da reunião de pesquisadores e pesquisadoras em diferentes momentos de suas carreiras, com o intuito de estudar questões relacionadas à sexualidade e juventude na contemporaneidade. Reuniu-se uma equipe de mais de 15 pesquisadores(as) de diferentes instituições, boa parte pela primeira vez em um trabalho conjunto. Muitos(as) sequer se conheciam. Desde início, já era o desejo que nos movia. Nosso corpo vibrátil ${ }^{1}$ que adentrava. Para alguns e algumas de nós, era inclusive a primeira vez no Sistema Socioeducativo, instituição efetivamente desafiadora pelos discursos e práticas que nela se inscrevem, e pelo lugar que ela ocupa na sociedade. Nos caminhos, muitas surpresas, angústias, desafios e esperanças, práticas, sentimentos e experiências sobre os quais discutiremos neste texto.

Muitas vezes os detalhes, a denominada "cozinha da pesquisa", como apontado por Becker (2007), é desconhecida da grande parte de jovens alunos(as) e pesquisadores(as) antigos(as) ou iniciantes, mesmo no campo das pesquisas qualitativas. Este autor lembra que muito dos bastidores da pesquisa, daquilo que acontece no cotidiano complexo do trabalho de campo, o passo a passo, as hesitações, incertezas, obstáculos, implicações e mudanças de rota, seja por atitude deliberada ou não por parte de pesquisadores(as) e/ou participantes de pesquisa, não costuma ocupar muitas páginas dos artigos acadêmicos. Quando muito, algumas linhas. Nessa direção, parece haver uma desvalorização ou pelo menos uma habitual recusa em valorizar - e apresentar - o conhecimento que é gerado no processo de investigação. A exposição, análise e debate sobre as dúvidas e obstáculos do campo de

\footnotetext{
${ }^{1}$ Para Suely Rolnik, nosso corpo tem duas capacidades. A cortical, "que corresponde à percepção que nos permite apreender o mundo em suas formas para, em seguida, projetar as representações de que dispomos, de modo a lhes atribuir sentido". A subcortical, "que por conta da repressão nos é mais desconhecida, nos permite apreender a alteridade em sua condição de campo de forças vivas que nos afetam e se fazem presentes em nosso corpo sob a forma de sensações. (...) Com ela, o outro é uma presença que se integra à nossa textura sensível, tornando-se, assim, parte de nós mesmos" (ROLNIK, 2006, p. 3). O corpo vibrátil corresponderia à segunda capacidade.
} 
pesquisa como ponto central do trabalho acadêmico é mais incomum e destituída de valorização no meio acadêmico.

Ao apostarmos na cartografia como prática ético-estético-política, este texto pretende partir e pôr em análise este fazer da pesquisa, suas mazelas, lacunas, dificuldades, surpresas, o que faz do trabalho um desafio, muitas vezes angustiante, mas intenso pelos encontros que propicia e pela disponibilidade para o novo. E é desses encontros que é possível usufruir de uma "colheita” de efeitos mais do que numa coleta de dados (KASTRUP; PASSOS, 2013).

Emerson Merhy (2004) conta de um encontro com um aluno que se sentia mal no seu lugar de pesquisador sem conseguir avançar muito na análise do que o deixava assim. O professor lhe disse que a "ideia de sujeito interessado não retratava o que ocorria" (p.22), visto que ele, além de "sujeito interessado é um sujeito implicado" (p.22). Ele estudara um sistema de saúde do qual tinha sido dirigente. Embora não seja nossa situação aqui, compartilhamos da sua provisória conclusão, que é mote para o seu texto: "você é um sujeito militante que pretende ser epistêmico e os desenhos de investigação que temos como consagrados no campo das ciências não dão conta desse tipo de processo. Necessitamos pensar melhor nisso e encontrar novas pistas" (MERHY, 2004, p.23). Aqui, convocamos e perturbamos pistas da cartografia exatamente como aposta do tipo de pesquisa que nos propomos fazer.

Este artigo tem por objetivo apresentar uma análise do cenário da pesquisa fundamentada no método cartográfico, realizada em três unidades de privação de liberdade do Sistema Socioeducativo no estado do Rio de Janeiro. Colocamos em questão os elementos processuais provenientes do trabalho de campo, realizado por três subequipes que focaram, cada uma, em uma unidade diferente, com vistas a destacar as estratégias coletivas de investigação-intervenção desenvolvidas ao longo dos dois anos de execução da pesquisa. Em segundo plano, o foco recai sobre as possibilidades e limites do trabalho de pesquisa em campo, especialmente, junto aos e às jovens, em razão da sua situação de institucionalizado(a), tutelado(a) e efetivamente mais limitado(a) em suas possibilidades de escolha e ação.

Nesse contexto, torna-se imprescindível tratar da experiência de pesquisar as histórias de vida desses(as) jovens, tematizando gênero e sexualidade em perspectiva com as especificidades do contexto institucional não apenas para os(as) jovens, mas para todos(as) os(as) envolvidos(as) na pesquisa. Buscamos assim pensar os limites, incertezas e as intranquilidades vivenciadas nesse campo (BARROS; KASTRUP, 2009).

As pesquisas de campo estão frequentemente voltadas para grupos específicos, os quais apresentam experiências singulares, muitas vezes marcadas por muitas dificuldades, e até mesmo por sofrimento. Numa investigação cartográfica, conhecer tais experiências equivale a transformá-las, o que coloca o desafio de pensar qual é o rumo a ser dado à intervenção e 
como fazer. Os sentidos adquiridos pela pesquisa dependem dos modos como o seu processo é incorporado, isto é, dos modos de sentir e agir mobilizados (SADE; FERRAZ; ROCHA, 2013, p.282)

Em nossas reuniões de equipe, vivências intensas e contações de histórias sempre calorosas em meio às dificuldades e sofrimentos que atravessam a vida dos e das jovens que encontramos nas três unidades que frequentamos durante quase dois anos no chamado Novo Degase - Departamento Geral de Ações Socioeducativas. Essa instituição tem como objetivo favorecer a "formação de pessoas autônomas, cidadãos solidários e profissionais competentes, possibilitando a construção de projetos de vida e a convivência familiar e comunitária” (RIO DE JANEIRO, 2017²).

Em muitos(as) dos(as) profissionais que atuavam nas unidades, fomos capazes de identificar uma intenção de que as práticas fossem realmente novas e orientadas por esta socioeducação descrita na proposta oficial e não apenas pela ótica da punição, porém, a realidade das unidades tenciona os objetivos do que é chamado de novo paradigma. São muitos olhares, pensamentos e práticas em disputa. A distância e a diversidade entre a proposta pedagógica do Novo Degase, nossos atravessamentos que constituem nossas noções de socioeducação e o cotidiano que observamos em nossa incursão durante esta pesquisa nos desafiou, impactou e provocou.

Neste texto, discorremos sobre diferentes afetações que nos atravessaram como equipe de pesquisa e de que forma elas têm nos provocado a pensar nas implicações éticas e metodológicas do nosso fazer, marcadas por um compromisso político com a vida desses(as) jovens e suas famílias. Seu cotidiano nas unidades e seu futuro na saída ajudam a desenhar os contornos da nossa pesquisa que precisa ser potente, do nosso ponto de vista, para (re)pensar a produção de um conhecimento engajado, ou um saber localizado, para utilizar uma expressão de Haraway (1995).

\section{MÉTODO}

A pesquisa foi desenvolvida por uma equipe de professores(as), pós-doutoranda, doutorandos(as), mestrandos(as) e estudantes da graduação da Universidade do Estado do Rio de Janeiro (UERJ), da Universidade Federal do Rio de Janeiro (UFRJ), da Fundação Osvaldo Cruz (Fiocruz) e do Instituto Federal do Rio de Janeiro (IFRJ) que se dedicaram à realização do estudo em três unidades do Degase. Tais unidades se destinam ao cumprimento de medidas socioeducativas de privação de liberdade, duas unidades são para jovens homens e uma para jovens mulheres. A pesquisa teve início em 2014 com as negociações junto ao Novo Degase para viabilização de autorizações judiciais para sua realização. Em abril de 2015 teve início o trabalho de campo que se estendeu até

\footnotetext{
${ }^{2}$ http://www.degase.rj.gov.br/quem_somos.asp Acesso em 20 de abril de 2018.
} 
dezembro de 2017. Durante este período participaram da pesquisa 68 jovens mulheres e 193 jovens homens, além de 91 profissionais.

O fenômeno do superencarceramento que o Brasil vive também atinge o Sistema Socioeducativo. Assim, todas as unidades encontravam-se superlotadas durante o período da pesquisa, a unidade feminina que tem capacidade para 44 moças, teve em média 70 internas; as unidades masculinas uma com capacidade para 90 jovens e a outra com capacidade para 180, mantinham no mínimo o dobro de sua capacidade. A estrutura física das unidades não comportava a superlotação. Em verdade, algumas delas, em especial as unidades masculinas, teriam dificuldades ainda que não estivessem superlotadas, pois apresentavam alojamentos sem ventilação adequada, precárias instalações elétricas, deficiência de vasos sanitários, problemas de encanamento e mesmo de esgoto a céu aberto, dentre outras questões, incluindo a falta de vagas para as escolas que se encontram dentro das unidades, o que viola o direito de educação que deveria ser garantido para os(as) jovens privados(as) de liberdade. O Ministério Público e a Defensoria Pública têm sido agentes importantes na fiscalização do que o Estado não tem feito no sentido de garantias mínimas dos direitos desses(as) jovens.

Enfatizamos que a pesquisa foi pensada a partir do método cartográfico (PASSOS; KASTRUP; ESCÓCIA, 2009) e realizamos entrevistas individuais e em grupo, variadas atividades em grupo com os e as jovens, além do uso do diário de campo para o registro sistemático das observações e afetações, fundamental para o processo de pesquisa. Podemos dizer que estes registros não se limitam a auxílios para a memória, mas próximos dos hypomnemata, de Foucault (1992), um material que possa levantar vozes e fazer calar. Assim, as anotações contribuem para a produção da pesquisa, que transforma para conhecer.

\begin{abstract}
essas anotações colaboram na produção de dados de uma pesquisa e têm a função de transformar observações e frases captadas na experiência de campo em conhecimento e modos de fazer. Há transformação de experiência em conhecimento e de conhecimento em experiência, numa circularidade aberta ao tempo que passa. Há coprodução. As observações anotadas são como um material para ter à mão" (BARROS; KASTRUP, 2009, p. 70).
\end{abstract}

Como apontado por Coimbra e Nascimento (2012), o diário de campo é um dispositivo importante para a análise de implicação, pois

trabalha com o cotidiano da pesquisa, historicizando-o, registrando-o, potencializando-o; ou seja, incluindo-o naquilo que normalmente fica fora dos relatos considerados científicos. [...] A escrita do diário de campo é, portanto, uma potente ferramenta para que esses acontecimentos ignorados, tidos como perturbadores e desviantes, sejam problematizados (COIMBRA; NASCIMENTO, 2012, p.131).

Assim, podemos dizer que as anotações e os registros do campo, assim como a gravação das entrevistas, quando isso é possível, fazem parte fundamental do que vamos colhendo no processo de 
pesquisa. Para a cartografia, "o diário de campo aparece como extremamente significativo no que tange a um percurso afetivo, político e metodológico" (DE GARAY, 2018, p.43). Nesse sentido,

experimentar afetos sinaliza a enunciação de outras formas de agir a partir dos modos de expressão que vamos percorrendo. Quando afetados pelas audições e visões, gostos e cheiros, toques de vidas que nos forçam a pesquisar na historicidade de um tempo que acontece, percebemos que nossas questões são feitas de vidas. Assim, exercitamos uma ética e expandimos nosso conhecer nas relações de uma vida de todos em nós, de uma vida de si com todos. Imanência de relações no corpo que cria passagens com o que força a experimentar nosso pensamento: afetos e perceptos que já não são de um ou de outro, mas da vida. Não precisamos mais temer o processo de estarmos afetados pelo acontecimento no ato de pesquisar, pois o que antes era dado como "ponto fraco" do pesquisador, agora marca uma condição indispensável do processo de pesquisar: a capacidade de afetar e afetar-se para que se criem os modos de expressar os sentidos de uma pesquisa" (LAZZAROTTO; CARVALHO, 2012, p.25).

Como a equipe era grande, os registros eram fundamentais para as trocas coletivas mensais. Tornavam-se disparadores de novas ideias tanto por quem escreveu o registro ou esteve na unidade, como por aquelas pessoas que tinham os primeiros contatos com os relatos. As dúvidas, os estranhamentos e as curiosidades com a narração de acontecimentos e sentimentos traçavam novos rumos para a pesquisa.

Cada unidade tinha um desenho diferente, fosse por conta das idades dos(as) jovens e das dinâmicas institucionais, fosse pela trajetória da direção, das formas mais pregnantes de se entender socioeducação, das negociações possíveis com as direções e com os(as) agentes socioeducativos para estabelecer a logística de participação na pesquisa. A superlotação já mencionada, bem como as forças sociais de violência que caracterizam a cidade, contribui para a tensão entre profissionais e jovens, assim como traz à tona as visões da justiça e o grau de seu engajamento na discussão e resolução de problemas que vão desde as desigualdades sociais do nosso país, em grande maioria, até o que realmente deveria ser judicializado. Igualmente, o trabalho realizado pelas equipes técnicas, compostas por psicólogas(os), assistentes sociais, pedagogas(os), terapeutas ocupacionais, médicas(os), enfermeiros(as), nutricionistas, e técnicas(os) de enfermagem, encontra-se extremamente burocratizado frente a à superlotação, o que muitas vezes impede que se envolvam em atividades para além da realização de relatórios de medida dos(as) jovens ou no atendimento de urgências.

Nesse contexto institucional, para muitas pessoas dos dois segmentos, questões de gênero e sexualidade seriam secundárias, pois haveria outras necessidades mais básicas para pensar e resolver nas unidades socioeducativas. Foi nesse campo que entramos com as nossas inquietudes sobre essas temáticas, encontrando barreiras na hora de priorizar as nossas propostas de pesquisa, mas também conhecendo pessoas que percebem como esses dispositivos são fundamentais nas trajetórias dos(as) jovens e na organização do cotidiano das unidades (D’ANGELO; DE GARAY, 2017), por exemplo, 
separando, classificando e hierarquizando espaços, tempos e corpos a partir de lógicas machistas e heteronormativas.

Durante meses, além de entrevistar profissionais, mergulhando nessas questões, realizamos várias atividades com jovens, utilizando disparadores como imagens com cenas que faziam emergir temáticas relacionadas à sexualidade, músicas, vídeos, realização de desenhos, dentre outros. O número de participantes por grupo variava em função da dinâmica de cada unidade e do que era possível na hora, visto que a movimentação dos(as) jovens pode não ser muito simples, dado o número reduzido de agentes nas unidades e a dinâmica institucional, pautada pela noção de Segurança (D'ANGELO, 2017).

As unidades do Novo Degase são muito diferentes entre elas, como dissemos, e possuem funcionamentos distintos, apesar de comporem, todas, o Sistema Socioeducativo do mesmo Estado, parte do Sistema de Garantia de Direitos. E talvez por isso o trabalho em cada unidade deu origem também a diferentes desdobramentos, que serão discutidos adiante. Portanto, confiar na potência do encontro, flexibilizar o desenho e os procedimentos da pesquisa diante dos cenários que se configuravam e em respeito aos(às) participantes, tornaram viável nossa entrada em campo e a realização da pesquisa.

Em uma das unidades masculinas, conseguimos articular o trabalho com os jovens a uma proposta de trabalho com profissionais, configurada em cursos de extensão sobre gênero, sexualidade, Direitos Sexuais e Direitos Reprodutivos. Nesses cursos utilizamos fragmentos de falas de jovens e de profissionais - retirando informações que pudessem identificar sua emergência-, como analisadores do próprio campo, recriando as forças que o atravessam para problematizá-las.

\section{RESULTADOS E DISCUSSÃO}

Um dos primeiros desafios expressados no campo, nas três unidades, foi uma certa desconfiança a respeito dos fazeres de pesquisa. As unidades do Novo Degase são frequentemente requisitadas por pesquisadores(as), e nesse sentido, ouvimos constantes relatos queixosos quanto ao fato de as pessoas acessarem a instituição, coletarem dados e irem embora, sem comprometimento com qualquer tipo de construção ou algum tipo de desdobramento que contribua para a instituição, os(as) profissionais e/ou os(as) jovens que nela se encontram. Desta forma, o original objetivo da pesquisa, que já vinha diretamente vinculado a um processo de extensão, permeou intensamente os nossos passos neste campo: a criação de um plano comum com os(as) participantes da pesquisa, entendido não como homogêneo, mas como um plano onde opera uma comunicação entre 
singularidades, compondo um mundo heterogêneo e partilhado (KASTRUP; PASSOS, 2013). Como apontado por Sade, Ferraz e Rocha,

Essa aposta guia a construção e manejo dos dispositivos da pesquisa, guia a forma como são estabelecidos e gerenciados os vínculos com os participantes. A construção de tais vínculos envolve criar condições para uma criação coletiva e partilhada de sentido, o que implica não só a possibilidade de colocação das questões que são próprias dos diversos atores envolvidos, mas também a abertura aos efeitos dos encontros que ali se estabelecem, pois é certo que os pesquisadores e os participantes possuem interesses, concepções e avaliações diferentes quanto ao que tem lugar no processo da pesquisa (SADE; FERRAZ; ROCHA, 2013, p.283)

Outra questão com a qual nos deparamos quando da entrada no campo foi um imaginário por parte da direção e equipe técnica das unidades masculinas, de que os jovens não falariam sobre sexualidade com as pesquisadoras. Contavam que os jovens não falavam desses temas com técnicas e professoras da escola dentro das unidades, pedindo inclusive para elas saírem das atividades em que se trataria do assunto. No entanto, para surpresa nossa e das(os) próprias(os) profissionais, os jovens falaram conosco. E bastante. Neste sentido, a aposta no encontro entre as singularidades como potência, como "zonas de indeterminação que nos lançam em trajetórias inventivas" (SADE; FERRAZ; ROCHA, 2013, p.284). Como os(as) autores(as) apontam, "confiar na potência de um encontro não se confunde com a ideia de completude, identidade ou convergência de interesses e finalidades" (idem). Sem idealizar esse encontro, sem buscar verdades, sem ter como norte (ou sul) descobrir o grau de realidade daqueles depoimentos e ideias. Estando conosco, a maioria dos jovens evitava falar palavrões, nomear a genitália e quando percebiam que muitas vivências e códigos não eram partilhados por nós, explicavam ou ainda tratavam de forma jocosa a situação, entoando a tal categoria "respeito" como elemento capaz de manter nossos encontros.

Pareceu-nos interessante que o diálogo sobre esses temas fosse mais aberto com pessoas que identitariamente não eram próximas, e que não partilhavam o mesmo espaço cotidiano. Certamente, o fato de nos posicionarmos constantemente como profissionais que não estavam ali para avaliá$\operatorname{los}\left(\right.$ as) e de ratificarmos que nossas conversas não teriam influência no relatório ${ }^{3}$, nos colocava em posição diferenciada em relação às técnicas. Ainda que em uma ocasião, querendo fazer valer o tempo que gastava conosco, um jovem pediu que constasse sim no relatório sua presença no grupo. Ele achava que esta era uma atitude que poderia contar a seu favor. No entanto, não é possível sermos ingênuas a ponto de acreditar que bastava nossa fala para que, como um "toque de mágica", eles "revelassem" tudo o que lhes parecesse interessante. Primeiro porque desconfiança, medo, arbitrariedade e códigos duros fazem parte do cotidiano dessas vidas intra ou extra muros, depois,

\footnotetext{
${ }^{3}$ Documento institucional preenchido pela equipe técnica discorrendo sobre a trajetória do(a) jovem dentro da unidade e levado a equipe de justiça com poder de influenciar sobre a extensão e tipologia da medida socioeducativa.
} 
porque não partimos da ideia de que há fatos, sentimentos, histórias pré-montados que devem ser revelados, uma espécie de essência que precisaria ser nos apresentada.

$\mathrm{Na}$ unidade feminina, por outro lado, nos primeiros contatos as jovens foram apresentadas como "mais perigosas", "mais violentas", com alto grau de periculosidade se comparadas aos jovens. Essas narrativas, em um primeiro momento, fomentaram certo temor na realização do trabalho, incluindo circular pela unidade e/ou ficar sozinhos(as) com as jovens, especialmente nos integrantes da equipe que não tinham experiência nesse campo. Porém, tão logo foram realizados os primeiros grupos, essa ideia de periculosidade premente foi se dissipando. Os grupos e entrevistas individuais com as jovens sempre ocorreram em um ambiente amistoso e tranquilo, onde os(as) pesquisadores(as) sempre tiveram a oportunidade de ficar sozinhos(as) com elas e nunca se sentiram ameaçados(as).

Podemos dizer que essas jovens fugiriam às expectativas tradicionais de gênero atribuídas às mulheres e a um modelo normativo de feminilidade, pela combinação entre transgressão de normas, das leis e o exercício da criminalidade. Assim, elas são vistas como "mais perigosas", "mais violentas" porque precisariam ser mais transgressoras que os homens para romper com essas expectativas e com a normatização do feminino. Ou então são vistas como vítimas, onde, como crianças, cometem crimes influenciadas por outros, via de regra, por homens, de preferência mais velhos e com quem se relacionam afetiva e/ou sexualmente.

Essas são formas de conceber as mulheres que cometem crimes que sofrem a influência histórica de duas correntes da criminologia do final do século XIX e início do século XX, a italiana Escola Positiva do Direito e o movimento Alienista francês. Ambas com um viés de gênero importante, onde a própria propensão ao crime poderia ser vista como feminina já que vinculada a uma natureza primitiva. Nessa perspectiva, a mulher criminosa seria pois, inferior duas vezes: inferior aos homens e às mulheres normais (RINALDI, 2015). As falas dos(as) profissionais parecem ratificar essas visões e, em um primeiro momento, foram capazes de gerar inquietação, angústia e mesmo medo em integrantes da equipe de pesquisa. Mas depois contribuíram para enriquecer as discussões sobre similitudes e diferenças entre as unidades femininas e masculinas e sobre as percepções e práticas cotidianas no trabalho realizado com jovens em cumprimento de medida socioeducativa.

Prescrições éticas como confiança e sigilo e aplicação do Termo de Consentimento Livre e Esclarecido (TCLE) foram manejadas de formas diferenciadas em cada uma das unidades em que estivemos. Pensar em sigilo em nossa pesquisa foi um tema extremamente difícil, pois na maioria das vezes tínhamos agentes socioeducativos presentes nas nossas conversas com os(as) jovens. Igualmente difícil era afirmar que somente podiam estar ali pela sua livre vontade, sendo que muitas negociações de logística interna institucional perpassam a obrigatoriedade de participação dos(as) jovens nas atividades, fato que nos demandou criatividade argumentativa junto à instituição e de 
estratégias junto aos(as) jovens para garantir que efetivamente a participação nas atividades da pesquisa fossem voluntárias.

Nas estratégias desenvolvidas foi necessário levar em conta as especificidades da própria situação de institucionalização, bem como a dinâmica de cada unidade. Os argumentos para seleção de jovens e do espaço que habitaríamos a cada dia se ancoravam em nome da Segurança, a nossa, sobretudo. Às vezes era possível ficarmos sozinhas com os jovens, outros dias não e isso variava entre as unidades e mesmo entre os dias de nossa estada.

O tempo reduzido do qual, muitas vezes, dispúnhamos para a realização dos grupos, somado à dinâmica dos e das jovens, que por vezes chegavam agitados(as), curiosos(as) sobre a pesquisa, aproveitando o momento para conversar entre eles(as), o fato de que vários(as) não sabiam ler e escrever, ou minimamente tinham muita dificuldade de leitura expressaram, por exemplo, que a leitura conjunta ipse litere do TCLE bem como a coleta individual de assinaturas poderia ser improdutiva. Deste modo, as equipes de pesquisa optaram por diferentes estratégias, tais como: explicar para os(as) jovens o conteúdo do TCLE de maneira informal buscando certificar-se de que tinham compreendido os termos e a autorização verbal para participação na pesquisa; outras equipes coletavam a assinatura do TCLE em entrevistas individuais tendo em vista a logística mais factível nessas circunstâncias. No entanto, mesmo nessas ocasiões nem sempre isso era viável ou eticamente possível manter alguns princípios devido à presença de um(a) agente socioeducativo(a) dentro da sala.

Importante observar que tais estratégias se deram dentro de um escopo de apreensão da pesquisa e seus aspectos éticos como um processo comunicativo. Autores(as) ao discutir aspectos éticos e bioéticos de pesquisa, especialmente com crianças e adolescentes, e populações institucionalizadas defendem a necessidade de que o TCLE deixe de ser apenas um registro concreto de uma autorização legal, passando a ser concebido como um processo comunicativo que precede a decisão autônoma de participar de um tratamento de saúde ou de pesquisa (NEIVA-SILVA; LISBOA; KOLLER, 2005). No entanto, é preciso considerar que com a restrição de liberdade a autonomia também diminui, o que nos obriga a repensar o conceito de ética que não estar em nenhum momento restrito à assinatura do documento.

Diniz e Correa (2001) ressaltam que a pura aplicação do TCLE e coleta de assinaturas como um processo mecânico, objetivando apenas o cumprimento da lei, já esteve nas bases de vários estudos perversos e abusivos. Nesse sentido, a preocupação maior das subequipes de pesquisa foi, respeitando o momento dos encontros, as dinâmicas institucionais e dos(as) jovens, garantir que os termos do TCLE fossem compreendidos pelos(as) participantes e a participação na pesquisa fosse voluntária, dentro de uma realidade institucional que em sua essência limitaria possibilidades de 
escolha. As estratégias adotadas parecem ter facilitado que os(as) jovens trouxessem seus questionamentos sobre a pesquisa. Perguntavam por exemplo detalhes sobre o que estávamos pesquisando, os motivos e o que seria feito com as informações que estávamos colhendo, bem como se encontramos as mesmas falas em outras unidades.

Alguns(as) jovens tinham inicialmente a expectativa de que nossa pesquisa seria apresentada ao juiz ou juíza responsável por seu caso, ou ainda de que sua participação seria comunicada ao juiz ou juíza, sendo anexada ao seu relatório. Podendo assim ter efeito positivo sobre a avaliação de seu caso a participação na mesma. Importante observar que mesmo após todas as explicações, inclusive de que essas expectativas não seriam atendidas, talvez surpreendentemente, nenhum(a) jovem desistiu de participar.

Ainda que todas as subequipes constantemente apresentassem a pesquisa como uma "pesquisa sobre sexualidade", em muitos momentos nossa pesquisa era entendida pelos(as) adultos como referente à prevenção em saúde, à saúde sexual e saúde reprodutiva e/ou sobre violência contra as mulheres, sem considerar a abordagem mais ampla, social, política e inclusive institucional com a qual nos posicionávamos e pensávamos as atividades. Por um lado, isso exprimia o quanto a abordagem da sexualidade segue estreitamente vinculada a uma perspectiva de saúde pública e a temáticas compreendidas como problemas de saúde na adolescência, especialmente em instituições educativas como escolas e as próprias unidades socioeducativas. Por outro, é importante termos claro que em certos momentos esse vínculo foi estratégico para continuarmos com as nossas ações, que assim não eram percebidas como desestabilizadoras da instituição.

\footnotetext{
A promoção da confiança, portanto, tem como desafio construir dispositivos que ensejem a sintonia, ou um regime de comunicação assentado fundamentalmente no plano das forças. $\mathrm{O}$ acesso à organização emergente da experiência promove senso de confiança, assim como o engajamento que o pressupõe. Isto é importante para fomentar a participação em processos de produção coletiva de conhecimento, como é o caso nas pesquisas cartográficas. Não se trata apenas da utilização de um determinado dispositivo, mas também de como manejá-lo de forma a criar uma zona de "interesse" que vincule e articule pesquisadores, pesquisados e o campo de pesquisa. A aposta é de que a produção de conhecimento a partir da instauração desse plano de experiência comum é acompanhada da produção coletiva de novas condições de existência (SADE; FERRAZ; ROCHA, 2013, p.289)
}

Essa confiança que foi se estabelecendo nas unidades também trouxe como surpresa uma certa liberdade das equipes dentro das unidades. $\mathrm{Na}$ unidade feminina, por exemplo, os(as) pesquisadores(as) não apenas não precisavam deixar seus pertences guardados em local específico destinado a guardar os pertences de pessoas externas à unidade e que terão contato com as jovens, como também logo tivemos autorização para gravar em áudio os encontros. A equipe técnica de início fazia recomendações quanto a termos cuidado com o celular porque as jovens não podiam usar e ao nos ver com os aparelhos para gravação das entrevistas poderiam nos pedir. Com o passar do tempo 
mesmo essas recomendações, de modo geral, cessaram, e nunca vivenciamos algo que cumprisse essas expectativas. Também nos lembravam, por vezes, quanto a impossibilidade de fazermos registros fotográficos das jovens. Nas unidades masculinas, também era recorrentemente lembrado que não podíamos deixar as nossas bolsas e celulares à vista dos jovens, pois eles poderiam roubar alguma coisa.

Com as(os) jovens também fomos construindo um caminho de confiança, de modo que em várias de nossas atividades houve relatos de episódios de violências por parte dos(as) agentes socioeducativos(as) e outras situações de violação de direitos que se, por um lado, falavam de confiança, vínculo e engajamento em relação à pesquisa, por outro suscitaram em nós questionamentos no que tange ao nosso lugar como pessoas engajadas na luta pela garantia dos Direitos Humanos. Como lidar com essas informações sem sermos rapidamente expulsas(os) da instituição e sem comprometermos a integridade de quem está ali no cotidiano foi um questionamento e uma angústia recorrente. Como gerar uma reação que não se veja motivada por uma vontade de destruição, mas por potência de singularização? (SADE; FERRAZ; ROCHA, 2013, p. 284).

São muitas as violências nesse campo: entre os(as) internos(as), entre eles(as) e agentes, entre agentes homens e agentes mulheres, entre diferentes categorias profissionais, entre direção e segmentos profissionais, ou seja, violências institucionais diversas e ainda a violência de Estado. Além dos relatos de violência que os jovens sofriam por parte de forças de segurança pública, milícias e facções do tráfico, e/ou que perpetuavam contra as companheiras e contra pessoas LGBT em suas comunidades, bem como das jovens sobre violências sofridas na família, pelos companheiros, pelo tráfico, pela força policial, dentre tantas outras. Em alguns momentos as(os) jovens faziam questão de mostrar para os(as) pesquisadores(as) as marcas da violência em seus corpos: cicatrizes, marcas de tiro e membros quebrados pela polícia em momentos de confronto ou da própria apreensão. A escuta, ou melhor, a vivência, dessas histórias de vida, em todas as unidades participantes da pesquisa, fez com que a equipe de pesquisa partilhasse constantemente suas angústias, nos interrogando continuamente sobre o que poderia ser feito nesta instituição tão controversa, com um cotidiano tão duro, constituído por desafios que nos pareciam (e talvez ainda pareçam), por vezes, intransponíveis.

No entanto, atendemos ao chamado de Judith Butler, quando coloca que:

a ética requer que nos arrisquemos precisamente nos momentos de desconhecimento, quando aquilo que nos forma diverge do que está diante de nós, quando nossa disposição para nos desfazer em relação aos outros constitui nossa chance de nos tornarmos humanos. Sermos desfeitos pelo outro é uma necessidade primária, uma angústia, sem dúvida, mas também uma oportunidade de sermos interpelados, reivindicados, vinculados ao que não somos, mas também de sermos movidos, impelidos a agir, interpelarmos a nós mesmos em outro lugar e, assim, abandonarmos o "eu" autossuficiente como um tipo de posse (BUTLER, 2015, p.171) 
Construções coletivas se constituem como possibilidades de ação e conexão e parecem eficazes no campo da garantia da ética. E ajudaram em momentos em que a necessidade de denúncia nos parecia premente. Como não cair no denuncismo, garantindo cuidado e respeito com as(os) participantes da pesquisa e com o campo de forma geral, resistências possíveis, criação de possibilidades de vida, e ainda assim não ser conivente com determinados abusos? Como Coimbra (2008, p.17) coloca, "há que inventar, criar, e a todo momento, tentar fortalecer as derivas, as fugas". Nesse sentido, buscamos fortalecer as linhas de fuga identificadas e pensar em novas possibilidades a partir de nossos encontros no campo.

Um desafio constante foi tentar dialogar com profissionais que, muitas vezes, compartilham um imaginário sobre os(as) jovens das unidades socioeducativas muito impregnado de estereótipos racistas, classistas, machistas (dentre outros) e que confluem em uma prática extremamente violenta, vinculada a um processo de "desumanização" desses(as) jovens. Práticas tão naturalizadas que se desvelavam durante a pesquisa aos nossos olhos, quando os(as) profissionais xingavam, gritavam, ameaçavam e desqualificavam os(as) jovens diante de nós ou para nós. De alguma forma, esses seus gritos também buscavam nos tirar da ingenuidade que acreditam que tinham em relação a esses jovens que insistíamos em proteger. Como lidar com os sentimentos que são evocados em nós pesquisadores(as) e como intervir sem ao mesmo tempo fecharmos as possibilidades de interlocução, de construção, ou mesmo sem fecharmos as portas institucionais?

Pudemos vivenciar momentos em que pessoas das equipes técnicas adotavam discursos e práticas discriminatórias e violentas para com os(as) jovens. De nossa parte, algumas vezes tivemos medo, o que nos martirizava e parecia nos deixar em um lugar impossível. Os e as agentes, muitas vezes, reproduziam olhares congelados sobre esses e essas jovens e ancoravam suas fala na experiência que tinham de viver lado a lado, inclusive em casa, com essas(es) jovens e suas famílias. Discursos que pareciam ganhar legitimidade em nome da Segurança e da ordem nas unidades. Portanto, seu papel disciplinador estaria fundamentado na própria descrição da função e reforçado pelo imaginário social, cada vez mais produzido por uma mídia que insiste em construir as figuras de perigosos. Função difícil esta dos agentes, que deve congregar Segurança e socioeducação: por que caminhos pode passar essa conjugação? Atribuições inconciliáveis? Dupla função?

Estudos têm se debruçado a investigar a questão de uma aparente impossibilidade conciliatória entre as funções Segurança e socioeducação (HERCULANO; GONÇALVES, 2011). Apontam como questão primeira o fato de que para o exercício da função de agente de segurança socioeducativo não existe exigência de formação específica e que, por outro lado, o próprio sistema não garante uma formação voltada para uma perspectiva mais flexível e mais próxima à perspectiva de Direitos Humanos sobre segurança e/ou sobre a própria socioeducação. "O indivíduo que a exerce foi 
aprovado em concurso público, mas não há um preparo direcionado ao desempenho da função, visto que a capacitação recebida apenas dá noções básicas das atribuições que irá executar" (HERCULANO; GONÇALVES, 2011, pag. 82).

Numa sociedade movida hegemonicamente por uma perspectiva punitiva, onde a Segurança está associada historicamente ao autoritarismo e a violências, seria necessário um trabalho constante e coletivo que tomasse como desafio, para todos e todas que habitamos a socioeducação, uma atuação educativa e novas formas de pensar a Segurança.

Outra questão que se colocava é que muitos(as) agentes se queixavam de serem constantemente alijados dos processos educativos institucionais (cursos, palestras, reuniões, dentre outros) e das discussões realizadas pelo corpo técnico. Muitos(as) técnicos(as), por sua vez, falam de seu desconforto e sensação de impotência diante de práticas autoritárias e violentas relacionadas na maior parte das vezes, à prática dos(as) agentes. Sentimos a animosidade entre categorias de profissionais e a polarização que nos atravessava também. Por outro lado, suas queixas, demandas e a pesada realidade em que se encontram todos(as) no cotidiano das unidades, desde os(as) jovens que nos denunciam as violências sofridas por profissionais, policiais e pela vida, como os profissionais que também expressam violências vistas, sofridas, infligidas nos inquietavam. O que fazer? Como contemplar os diferentes segmentos e exatamente com o quê?

Como já mencionamos, como parte da pesquisa, tivemos a oportunidade de oferecer dois cursos de extensão em uma das unidades masculinas, demanda da unidade, um sobre metodologia de trabalho sobre gênero e sexualidade com jovens, outro sobre questões em torno dos Direitos Sexuais e Reprodutivos, especificamente do uso do preservativo. Igualmente, a partir de uma demanda da Escola de Gestão Socioeducativa, dois módulos sobre Gênero e Sexualidade no curso de formação continuada da Escola, que se bem tiveram mais participação de pessoas das coordenadorias e da gestão, também contaram com a participação de profissionais das unidades, de diferentes segmentos, o que gerou um diálogo intenso sobre as temáticas que trabalhamos na pesquisa, nos ajudando a mergulhar nas nossas análises. A própria temática dos cursos, onde abordávamos sexualidade, gênero, violência, Direitos Humanos, muitas vezes já inquietava nossas(os) interlocutoras(es), causando até mesmo indignação. Éramos frequentemente interpelados(as) sobre a importância dessas discussões diante de uma realidade onde "falta vaso sanitário e papel higiênico para os adolescentes". Gênero e sexualidade, embora atravessassem e até mesmo organizassem a instituição, apareciam como atributos de luxo.

Muitas vezes, gênero e sexualidade simplesmente não eram percebidas como temáticas pertinentes ao cotidiano institucional. Salvo se vinculadas a questões tomadas como de saúde pública, como prevenção de Infecções Sexualmente Transmissíveis (IST) / Human Immunodeficiency Virus 
(HIV) / Acquired Immunodeficiency Syndrome (Aids) ou de gravidez na adolescência. E nos perguntávamos a todo o tempo como lograr que esses temas se tornassem importantes para além da sexualidade e gênero tratados tão somente pelo enfoque saúde-doença, prevenção-intervenção e Direitos Humanos apenas quando vinculado a saúde sexual e/ou saúde reprodutiva. Questionamentos que partilhamos com a Escola de Gestão Socioeducativa e com gestão e equipes das unidades, onde de diversas maneiras encontramos eco, seja em angústias, seja em propostas para novas atividades no futuro, de maneira a seguir investindo nessas temáticas conjuntamente.

Assim, esse eco permitiu conhecer de perto as iniciativas e articulações de pessoas de todos os segmentos, assim como dos próprios jovens, no sentido de problematizar o silenciamento de questões sobre gênero e sexualidade, estabelecido na naturalização da dureza das normas que delimitam as relações institucionais. Foi possível, dessa forma, encontrar diálogos, movimentos contrários à burocratização e à violência, questionamentos a classificações e práticas machistas, heteronormativas e racistas, atividades para discutir gênero e sexualidade e garantir Direitos Sexuais e Reprodutivos, dentre outros caminhos possíveis que encontraram em nós uma parceria para legitimar, sistematizar, adensar e enriquecer alternativas ao modo cristalizado de se relacionar nas unidades e de pensar socioeducação.

\section{CONSIDERAÇÕES FINAIS}

Uma parte extremamente importante do nosso percurso foi debruçarmo-nos sobre as implicações éticas da nossa inserção na unidade, que se configuram também como problemas políticos (COUTINHO, 1997). Para a perspectiva cartográfica, a dimensão ética se refere ao plano das diferenças que se fazem em nós e na afirmação do devir - potência ativa - a partir dessas diferenças.

Assim, ao nos permitirmos afetar e ser afetadas(os), construímos a proposta de suscitar condições para dialogar, para falar de si/nós em outros registros além do abuso de poder e da impotência ou ainda da falta. Nossa perspectiva era promover que as pessoas se pensassem a partir de agenciamentos coletivos, de exercícios de autonomia e dignidade.

Desta forma, nos apoiando no trabalho de Coutinho (1997) sobre a relação com as(os) interlocutoras(as) com as(os) quais trabalhamos, pensamos que a nossa responsabilidade não era com todos(as) os(as) jovens em privação de liberdade de forma geral, nem com todos(as) os(as) profissionais do Degase, mas com esses(as) com quem conversamos, com os(as) que se dispuseram a estar conosco, com esses(as) que naquele momento circulavam naquelas unidades que buscamos e acreditamos, de certa forma, termos desassossegado. Desassossegamos a nós mesmas. Não há 
dúvidas. E as perturbações que provocamos, tivemos que nos haver com algumas delas transformadas em novas demandas que continuamos a atender com prazer. Com prazer, angústias, medos e, sobretudo, tomadas pelo desafio que é compor com o(a)-outro(a)-em-nós. E dessa forma, quem sabe, produzir vibrações e intensidades que reverberem para além do que os nossos olhos podem perceber.

\section{REFERÊNCIAS}

BARROS, Lílian; KASTRUP, Virgínia. Cartografar é acompanhar processos. In: PASSOS, Eduardo; KASTRUP, Virgínia; ESCÓSSIA, Liliana. (Orgs.). Pistas do método da cartografia: pesquisa-intervenção e produção de subjetividade. Porto Alegre: Sulina, 2009. p. 52-75.

BECKER, Howard. Segredos e truques da pesquisa. Rio de Janeiro: Zahar, 2007.

BUTLER, Judith. Quadros de guerra. Quando a vida é passível de luto? Civilização brasileira: Rio de janeiro. 2015, $287 \mathrm{f}$.

COIMBRA, Cecília. Práticas da psicologia social como(o) movimentos de resistência e criação In: BONAMIGO, I.; TONDIN, C.; BRUXEL, K. (Org.). As práticas da psicologia social como movimentos e resistência e criação. Porto Alegre: Abrapso Sul, 2008, p.11-18.

COIMBRA, Cecília; NASCIMENTO, Maria. Implicar. In: FONSECA Tania; NASCIMENTO Maria; MARASCHIN, Cleci (Orgs.) Pesquisar na diferença: um abecedário. Porto Alegre: Sulina, 2012, p. 129-131

COUTINHO, Eduardo. O Cinema documentário e a escuta sensível da alteridade. Projeto História. v. 15, p. 165-191, 1997.

D'ANGELO, Luisa. Entre "sujeita-mulher" e "mulher de bandido": produções de feminilidades em contexto de privação de liberdade. 2017. 154f. Dissertação (Mestrado em Psicologia Social). Instituto de Psicologia, Universidade do Estado do Rio de Janeiro, Rio de Janeiro, 2017.

D'ANGELO, Luisa; DE GARAY, Jimena Hernández. Sexualidade, um direito (secundário)?

Atravessamentos entre sexualidade, socioeducação e punição. Revista Plural v. 24, n. 1, p. 78-104, 2017.

DE GARAY, Jimena Hernández. O Adolescente dobrado: cartografia feminista de uma unidade masculina do Sistema Socioeducativo do Rio de Janeiro. 2018. 442 f. Tese (Doutorado em Psicologia Social). Programa de Pós-graduação em Psicologia Social, Universidade do Estado do Rio de Janeiro, Rio de Janeiro. 2018. 
DINIZ, Debora e CORREA, Marilena. Declaração de Helsinki: relativismo e vulnerabilidade. Cad. Saúde Pública, Rio de Janeiro, 17(3):679-688, mai-jun, 2001. Disponível em: http://www.scielo.br/pdf/csp/v17n3/4650.pdf. Acesso em: 12 de fevereiro de 2018.

FOUCAULT, Michel. O que é um autor? Lisboa: Vega/Passagens, 1992.

HERCULANO, José Antonio, GONÇALVES, Marcelo. Educador social: segurança e socioeducador, a conciliação. Serv. Soc. Rev., Londrina, v.14, n.1, p. 74-101, Jul./Dez. 2011. Disponível em: http://www.uel.br/revistas/uel/index.php/ssrevista/article/view/10674. Acesso em: 23 de abril de 2018.

HARAWAY, Donna. Saberes localizados: a questão da ciência para o feminismo e o privilégio da perspectiva parcial. Cadernos Pagu, v.5, 1995, 7-41. Disponível em:

https://periodicos.sbu.unicamp.br/ojs/index.php/cadpagu/article/view/1773. Acesso em 22 de abril de 2018.

KASTRUP, Virgínia, PASSOS, Eduardo. Cartografar é traçar um plano comum. Fractal, Rev. Psicol, v.25, n.2, p.263-280, Maio/Ago 2013.

LAZZAROTTO; Gislei. CARVALHO Julia. Afetar. In: FONSECA, Tania; NASCIMENTO, Maria; MARASCHIN, Cleci. (Orgs.). Pesquisar na diferença: um abecedário. Porto Alegre: Sulina, 2012. p.23-25

MERHY, Emerson. Prefácio: O conhecer militantes do sujeito implicado: o desafio de reconhece-lo como saber válido. In: FRANCO, Tulio B. et al. (orgs.) Acolher Chapecó - uma experiência de mudança do modelo assistencial, com base no processo de trabalho. São Paulo: Hucitec, 2004.

NEIVA-SILVA, Lucas; LISBOA, Carolina; KOLLER, Sílvia Helena. Bioética na pesquisa com crianças e adolescentes em situação de risco: dilemas sobre o consentimento e a confidencialidade. Dst - J Bras Doenças Sex Transm, Niteroi, v. 3, n. 17, p.201-2016, jul. 2005. Disponível em: $<$ http://www.dst.uff.br/revista17-3-2005/bioetica-na-pesquisa.pdf $>$. Acesso em: 5 de fevereiro de 2018.

RIO DE JANEIRO. O Novo Degase: Departamento Geral de Ações Socioeducativas. Secretaria de Estado de Educação. Quem somos. Disponível em:

$<$ http://www.degase.rj.gov.br/quem_somos.asp>. Acesso em: 8 maio 2017.

PASSOS, Eduardo; KASTRUP, Virginia. Sobre a validação da pesquisa cartográfica: acesso à experiência, consistência e produção de efeitos. Fractal, Rev. Psicol, v.25, n.2, p.391-413, Maio/Ago 2013. 
PASSOS, Eduardo; KASTRUP, Virginia e ESCÓSSIA, Liliana. Pistas do método da cartografia: Pesquisa-intervenção e produção de subjetividade. Porto Alegre: Editora Sulina, 2009.

RINALDI, Alessandra. A sexualização do crime no Brasil: um estudo sobre criminalidade feminina no contexto de relações amorosas [1890-1940]. 1 $^{\text {a }}$ ed. Rio de Janeiro: Mauad X/ Faperj, 2015. 222 p.

ROLNIK, Suely. Geopolítica da cafetinagem. 2006. Disponível em: https://www.pucsp.br/nucleodesubjetividade/Textos/SUELY/Geopolitica.pdf. Acesso em: 16 de abril de 2018.

SADE, Christian; FERRAZ, Gustavo; ROCHA, Jerusa. O ethos da confiança na pesquisa cartográfica: experiência compartilhada e aumento da potência de agir. Fractal, Rev. Psicol., v. 25, n. 2, p. 281-298, Maio/Ago 2013

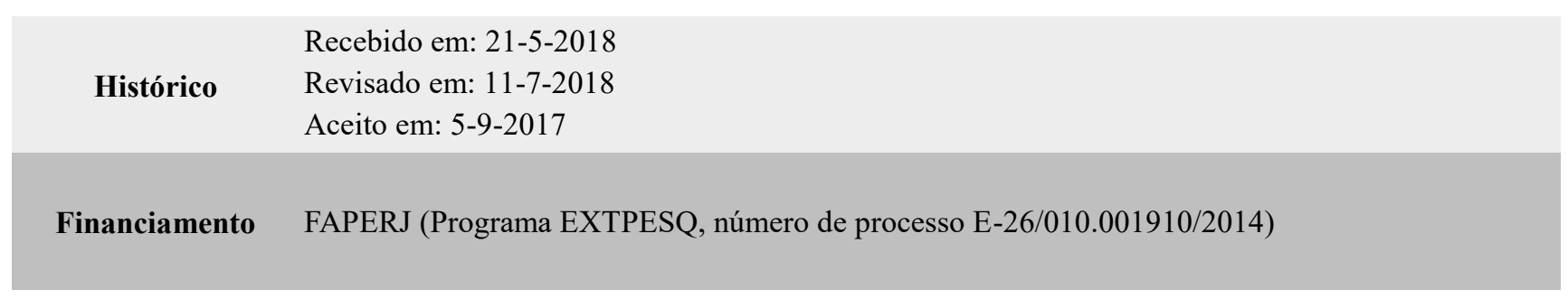

